\title{
The effects of FSH and activin A on follicle development in vitro
}

\author{
Davina A Cossigny, Jock K Findlay and Ann E Drummond \\ Prince Henry's Institute of Medical Research, PO Box 5152, Clayton, Victoria 3168, Australia \\ Correspondence should be addressed to A E Drummond; Email: ann.drummond@princehenrys.org
}

\begin{abstract}
Numerous studies have reported on the roles of activins in gonadal regulation; however, little is known about their specific roles in early folliculogenesis. Ovarian follicular growth was investigated in 10-day cultures of day 4 postnatal whole ovaries treated with activin $\mathrm{A}$ $($ ActA; $50 \mathrm{ng} / \mathrm{ml})$, with or without FSH $(100 \mathrm{ng} / \mathrm{ml})$ in vitro. We hypothesized that treatment with ActA \pm FSH would affect rates of growth and atresia in follicles. None of the treatments affected primordial follicle activation, and antral follicles were not observed after 10 days in culture. Primordial follicle numbers from all treatment groups were $\sim 20 \%$ of those in day 4 fresh ovaries, indicating that activation had occurred. In the presence of ActA, preantral follicle numbers increased significantly $(P<0.0001)$. ActA alone decreased the proportion of atretic follicles in the primary and preantral classes, whereas the combined treatment of ActA $+F S H$ increased the proportion of atretic preantral oocytes. Real-time PCR analysis revealed that follistatin, FSH receptor, and activin $\beta A$ and $\beta B$ subunits were all expressed at significantly higher levels in the ActA-only treated group but not in the ActA+FSH group. Here, we report novel findings supporting the role of FSH in primordial follicle survival through an action on apoptosis and a stimulatory role of ActA in the primordial to primary and preantral stages of follicle development, suggesting an inhibitory action of activin on oocyte apoptosis.

Reproduction (2012) $143221-229$
\end{abstract}

\section{Introduction}

Folliculogenesis is the process of follicle growth and oocyte maturation. Germ cell numbers in the rodent are established before birth. Shortly thereafter, primordial follicles form and begin to move through primordial, primary, and preantral stages of development. Folliculogenesis can be divided into two principle phases: 1) the gonadotropin-independent phase and 2) the gonadotropin-dependent phase. The first phase is associated with primordial to preantral follicles and entails growth and differentiation of the oocyte and granulosa cells; pituitary gonadotropins are not essential for this growth phase, although they may influence growth. The second phase is associated with antral to ovulatory follicles and largely depends on the presence of circulating levels of follicle-stimulating hormone (FSH) and luteinizing hormone (LH). This stage marks follicle responsiveness to $\mathrm{FSH}$ and $\mathrm{LH}$ and involves the growth and development of granulosa cells and the recruitment of theca cells. The factors that govern oocyte and primordial follicle development during the gonadotropin-independent phase remain unclear; however, increasing evidence has suggested that growth factors such as transforming growth factor $\beta 1$ (TGFB1) and activins play key roles (Woodruff \& Mather 1995, Knight 1996, Vendola et al. 1998, Rosairo et al. 2008).

Activins are growth and differentiation factors belonging to the TGFB superfamily. They consist of dimers of two inhibin $\beta$ subunits ( $\beta A$ and/or $\beta B$ subunits) linked by disulfide bonds (Vale et al. 1986) and are produced by a variety of tissues and organs in the body (reviewed in Massague (1998)). Mammalian ovaries express both types of activin receptors (activin receptor type-1B (ACVR1B; ALK4) and ActRIIA/B), and in the rat, both $\beta A$ and $\beta B$ subunits are highly expressed in granulosa cells of developing follicles, while theca cells express little or no $\beta$ subunit mRNAs (Meunier et al. 1988, Roberts et al. 1993, Drummond et al. 1996, 2002). In contrast, the oocyte does not appear to express either subunit but does exhibit both type I and type II receptors (Sidis et al. 1998). During folliculogenesis, the differentiation status of granulosa cells determines the response to activins (Findlay 1993). Activin is produced by granulosa cells of primary to tertiary follicles of the ovary (Rabinovici et al. 1992, Zhao et al. 2001). It has been found to promote the release of FSH from the anterior pituitary (Katamaya et al. 1990). In the ovary, it plays a role in promoting aromatase activity, antral cavity formation, and granulosa cell proliferation (Findlay 1993, Mizunuma et al. 1999, Zhao et al. 2001). Additionally, activin is antagonized by follistatin and inhibin binding to its receptors (Lewis et al. 2000).

Numerous studies have shown the roles of activins in gonadal regulation (Meunier et al. 1988, Woodruff \& Mather 1995, Drummond et al. 2002, Drummond 2005); however, little is known about their specific 
roles in early folliculogenesis. In the rat, primordial follicles are formed within 2-3 days of birth and continue to grow thereafter (Rajah et al. 1992). Consequently, the follicle reserve at this time comprises mainly primordial follicles with little or no apoptosis being observed (Gosden \& Telfer 1987), and these postnatal ovaries provide good models for in vitro investigations of follicle growth. Following our initial investigations on the role of TGFB1 in early ovarian follicle development (Rosairo et al. 2008), we again utilized a whole postnatal ovary organ culture to investigate the role of activin in follicle development. We hypothesized that activin A (ActA) alone or in combination with $\mathrm{FSH}$ will have an effect on the incidence of follicle atresia and the growth rate of preantral follicles. Our findings demonstrate that ActA alters follicle development, resulting in an increased number of preantral follicles. Increased atresia in oocytes of preantral follicles was observed when ovaries were treated with ActA in combination with FSH. These data further support a novel role of FSH in decreasing apoptosis in vitro in the primordial follicle pool (Rosairo et al. 2008). Our findings demonstrate the importance of activin in driving follicle development during early folliculogenesis.

\section{Results}

\section{ActA stimulates preantral follicle development in cultured whole ovaries}

After 10 days in culture, the number of primordial follicles was similar across all treatment groups (control, $\mathrm{FSH}, \mathrm{Act} \mathrm{A}$, and $\mathrm{FSH}+\mathrm{Act} \mathrm{A})$. When compared with the number of primordial follicles in fresh ovaries from 4-day-old rats, there was a statistically significant decrease across all four treatment groups consistent with primordial follicle activation (Fig. 1A). Primary follicles from all treatment groups increased significantly relative to those in day 4 fresh ovaries, although the differences between treatments were not statistically significant (Fig. 1B). Day 4 fresh ovaries had significantly lower number of preantral follicles compared with all treatment groups. A significant increase in preantral follicle number was observed in ovaries treated with FSH or ActA alone $(P<0.05$ and $P<0.001$ respectively) compared with fresh ovaries (Fig. 1C). Preantral follicle numbers in in vitro controls had similar numbers to the FSH-treated groups. The ovaries contained a substantially higher number of preantral follicles in the group treated with ActA alone than all other treatment groups $(P<0.05$; Fig. 1C). However, combined FSH+ActA treatment significantly reduced the number of preantral follicles compared with the number seen in ovaries treated with either FSH alone or ActA alone. No antral follicles were observed in ovaries from any of the control or treated groups. Table 1 shows the percentage proportions of each follicle class within each treatment group as well as day 4 fresh ovaries.

\section{ActA decreases the amount of apoptosis in primordial, primary, and preantral follicles in cultured whole ovaries}

TUNEL analysis investigated follicular atresia occurring within cultured whole ovaries (Fig. 2). We established that the percentage of healthy follicles (calculated from oocyte-positive cells) was always greater than that of atretic follicles in cultured whole ovaries from control, FSH-treated, and ActA-treated groups in all follicle
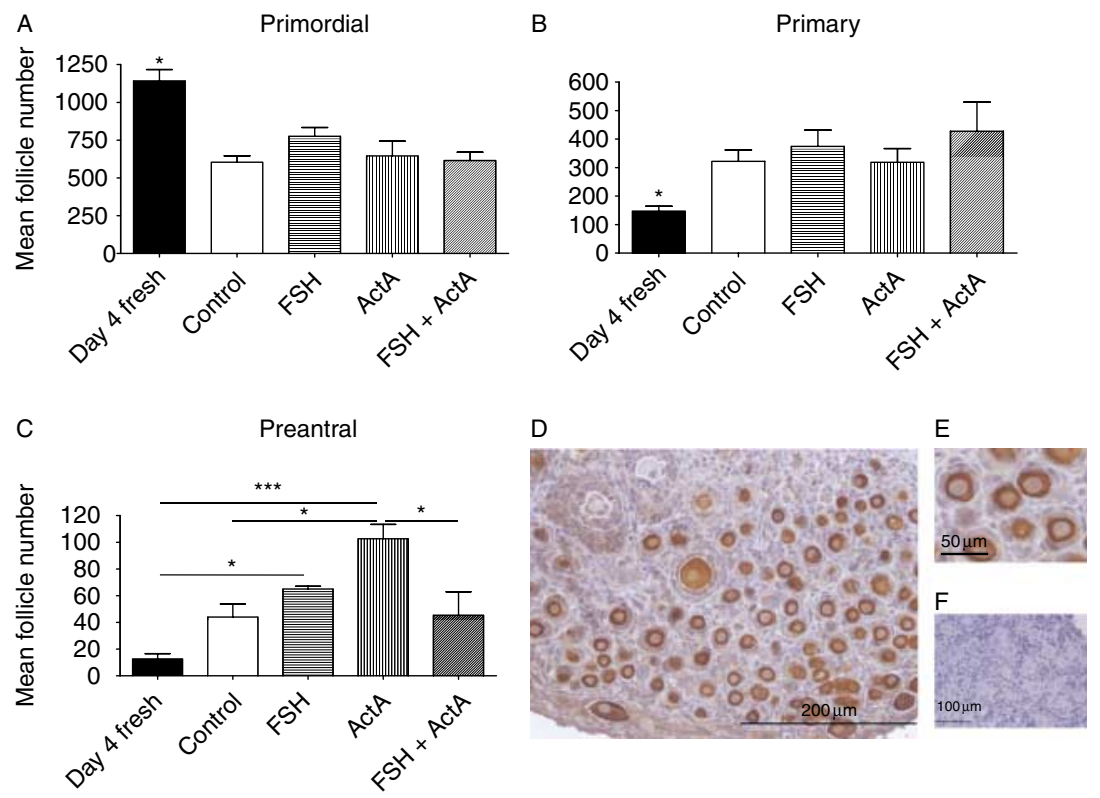

Reproduction (2012) 143 221-229
Figure 1 Follicle numbers in whole ovaries after 10 days of culture with media only (control), FSH, activin $\mathrm{A}(\mathrm{Act} \mathrm{A})$, or $\mathrm{FSH}+$ activin $\mathrm{A}$, compared with day 4 fresh ovaries. (A) Primordial follicles, (B) primary follicles, and (C) preantral follicles. Mean \pm S.E.M. $(n=3)$. Statistical significance represented as ${ }^{*} P<0.05$ and ${ }^{* * *} P<0.001$. Immunohistochemistry depicting germ cell staining of mouse Vasa homolog $(\mathrm{MVH})$ protein that was used to assist follicle counting and categorization of ovaries at the end of the 10-day culture period. (D) Ovarian section from an FSH-treated culture $(\times 40)$, (E) ovarian section from an FSH-treated culture $(\times 100)$, and $(F)$ negative control section; $\mathrm{MVH}$ antibody omission. 
Table 1 Proportion of follicle class represented as a percentage of total follicle numbers from day 4 fresh ovaries (before 10 days of culture) and all treatment groups (after 10 days of culture).

\begin{tabular}{lccccc}
\hline & $\begin{array}{c}\text { Day 4 } \\
\text { fresh }(\%)\end{array}$ & $\begin{array}{c}\text { Control } \\
(\%)\end{array}$ & $\begin{array}{c}\text { FSH } \\
(\%)\end{array}$ & $\begin{array}{c}\text { Activin A } \\
(\%)\end{array}$ & $\begin{array}{c}\text { FSH+ } \\
\text { activin A }(\%)\end{array}$ \\
\hline Primordial & 88 & 62 & 65 & 60 & 57 \\
Primary & 11 & 33 & 29 & 30 & 39 \\
Preantral & 1 & 5 & 6 & 10 & 4 \\
\hline
\end{tabular}

classes, i.e. primordial, primary, and preantral classes (Fig. 3, Table 2). In day 4 fresh ovaries, there was minimal apoptosis with only $8 \%$ of primordial follicles, $1 \%$ of primary follicles, and $0 \%$ of preantral follicles (data not shown) staining positively. Primordial follicles from ovaries treated with $\mathrm{FSH}$ alone or with $\mathrm{FSH}+\mathrm{ActA}$ showed a higher proportion of healthy follicles compared with controls, while primary follicles from ovaries treated with ActA alone or with $\mathrm{FSH}+$ ActA were substantially increased compared with controls (Fig. 3, Table 2). Ovaries treated with ActA contained fewer apoptotic primordial follicles compared with controls. Primary and preantral follicles from ActA-treated ovaries exhibited a considerable increase in the proportion of healthy follicles when compared with all other groups (Fig. 3C, Table 2). However, when ovaries were treated with a combination of FSH+ActA, there was a notable increase in the percentage of atretic vs healthy follicles in the preantral follicle population (Fig. 3D, Table 2). Interestingly, this was the only treatment where the percentage of atretic follicles was greater than that of healthy follicles. Treatment of cultured ovaries with FSH also appeared to be decreasing apoptosis in the primordial follicle pool by $25 \%$ when compared with controls.

\section{Fst, ActA subunit, ActB subunit, and FSH receptor mRNA expression is upregulated in ovaries treated with ActA}

Cultured whole rat ovaries receiving media alone (control), ActA $(50 \mathrm{ng} / \mathrm{ml}), \mathrm{FSH}(100 \mathrm{ng} / \mathrm{ml})$, or a combination of FSH+ActA were all found to express follistatin, activin $\beta A$ and $\beta B$ subunits, and FSH receptor (FSHR) mRNAs. Expression of each mRNA was found to be substantially higher in ovaries treated with ActA compared with all other treatment groups $(P<0.05$; Fig. 4). Follistatin and FSHR mRNA expression were 40- and 146-fold, respectively, greater in ovaries treated with ActA relative to the control (Fig. $4 A$ and D). The mRNA expression levels of activin $\beta A$ and $\beta B$ subunits were the highest in ovaries treated with Act $A$, which were, respectively, 24- and 80-fold higher than the control group (Fig. 4B and C). Furthermore, there was a significant decrease in mRNA expression levels in ovaries treated with FSH+ActA. This was consistent across all mRNAs tested.

\section{Discussion}

In this study, we investigated the role of ActA (in the presence or absence of FSH) in follicle growth and developmental transition using an established in vitro organ culture system that models early folliculogenesis (Rosairo et al. 2008). At the end of a 10-day culture period, follicles were classified as primordial, primary, or preantral and were examined for apoptosis. No antral follicles were present. In ovaries cultured with $\mathrm{FSH}, \mathrm{ActA}$, or a combination of both, there was no significant effect on primordial follicle activation relative to the untreated control group. However, when compared with day 4 fresh ovaries, there was a significant decrease in primordial follicle number $(P<0.001)$ consistent with follicle activation in vitro. Studies by Ding et al. (2010) showed that ActA had a dose-dependent inhibitory effect on the activation of human primordial follicles in vitro. The authors suggest that activin may play an inhibitory role in the recruitment and activation of primordial follicles in humans. However, in our analyses of ActA action, primordial follicles were neither stimulated nor inhibited in these processes using the same concentration of activin as reported by Ding et al. (2010). Our analyses revealed that FSH decreased apoptosis occurring in vitro in the primordial follicle pool (14 vs 38\%), supporting our
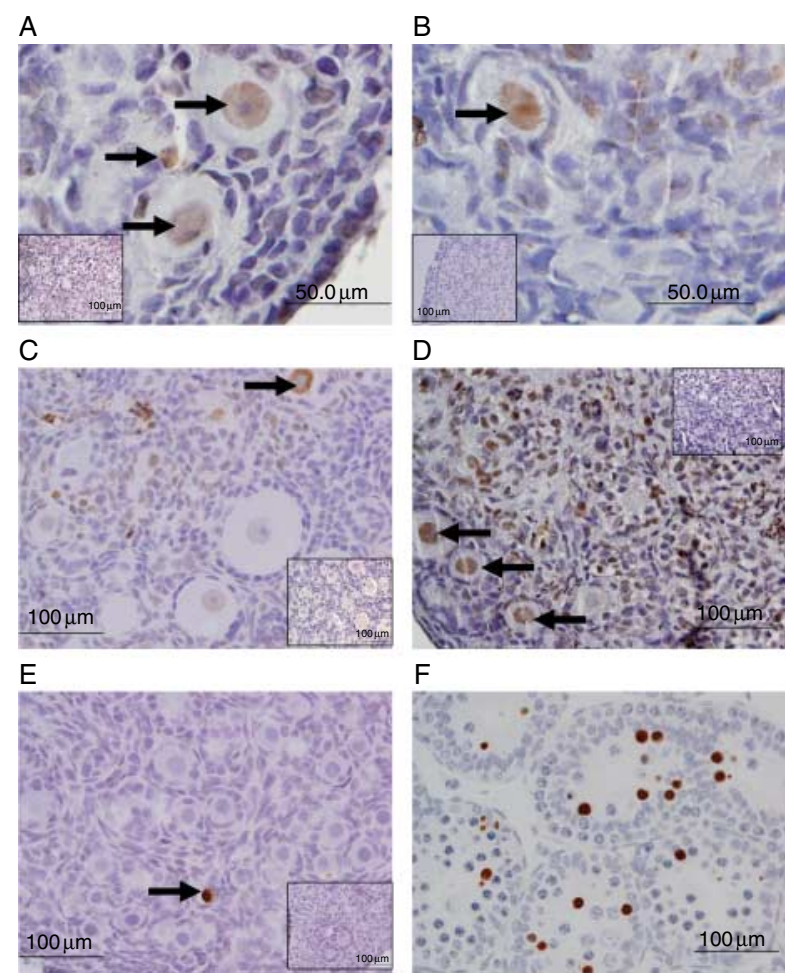

Figure 2 TUNEL staining on ovarian sections taken from whole ovaries following 10 days of culture. TdT-positive cells are depicted by brown staining shown by arrows. (A) Control, (B) FSH, (C) activin A, (D) FSH+ activin $A$, (E) day 4 fresh ovary, and (F) positive control, immature rat testis. Insets depict negative controls. 

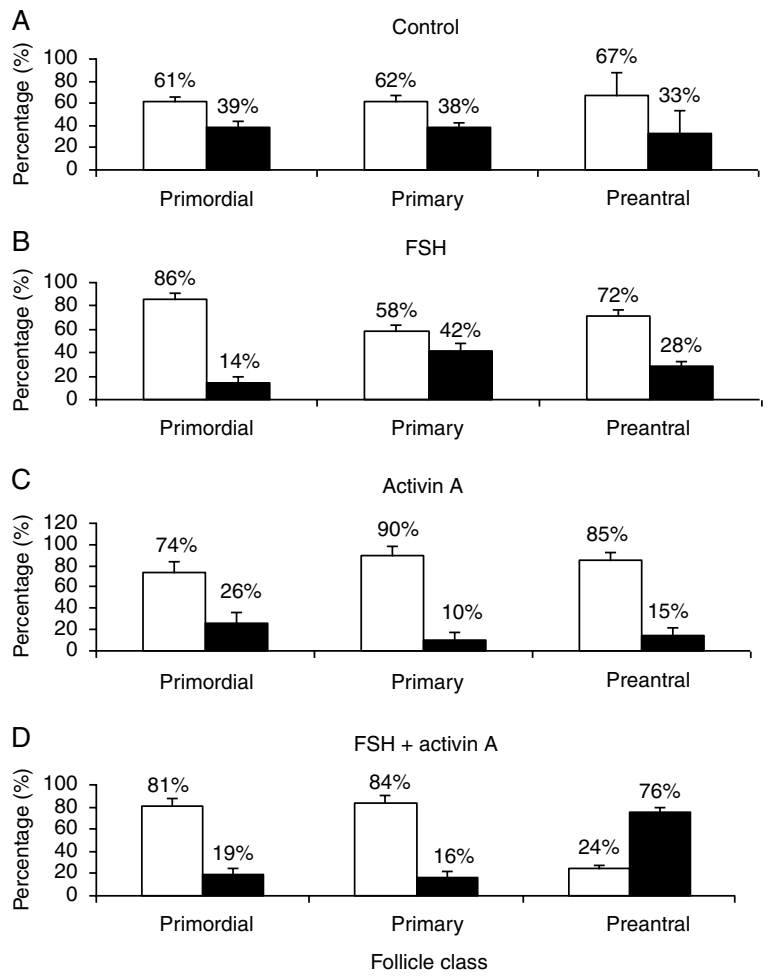

Figure 3 Percentage proportions of healthy (white) vs atretic (black) follicles after 10 days of culture. (A) Control, (B) FSH, (C) activin A, and (D) $\mathrm{FSH}+$ activin $\mathrm{A}(n=3)$. Mean \pm S.E.M.

previously published data (Rosairo et al. 2008). This effect is likely to be indirect because FSHR is known to be located on granulosa cells, not on oocytes. Furthermore, this stage of follicle development is known to be gonadotropin independent, with rat ovaries showing sensitivity to $\mathrm{FSH}$ for the first time at 4-5 days of age in vitro (Funkenstein et al. 1980, Sokka \& Huhtaniemi 1990). These studies support a role for FSH in primordial follicle survival via a reduction in apoptosis.

Our results also suggest that ActA alone displays antiapoptotic properties as there was a substantially higher percentage of healthy vs atretic primary follicles in ovaries treated with ActA (90 vs $62 \%$ ). Preantral follicles from ActA-treated ovaries also exhibited a considerable increase in the proportion of healthy vs atretic follicles, supporting a role for ActA in reducing atresia. These results are consistent with previous findings whereby mice administered with rh-ActA showed a $30 \%$ increase in the primordial follicle population, suggesting that activin increased follicle survival while decreasing apoptosis (Bristol-Gould et al. 2006). However, the increased number of follicles formed after activin injections in vivo did not persist in puberty, with follicle numbers returning to control levels. It was suggested that there was an optimal number of oocytes available at puberty and when this threshold was exceeded, oocyte quality was jeopardized (Bristol-Gould et al. 2006). Furthermore, addition of ActA significantly reduced the number of atretic follicles developing in cultured goat cortical tissue, thus promoting the in vitro survival and growth of activated follicles (Silva et al. 2006). We propose that one of the mechanisms by which ActA treatment led to a significant expansion of the preantral follicle population in our model was by decreasing apoptosis. Activin may block apoptotic pathways that result in follicle death (atresia). This does not exclude the possibility that ActA stimulates preantral folliculogenesis by actions on somatic cell differentiation and proliferation as has been shown for preantral follicles (Drummond et al. 1996, Silva et al. 2006).

ActA significantly increased the number of preantral follicles relative to day 4 fresh ovaries, control, and combined treatment group $(P<0.05)$, consistent with its role in stimulating follicle growth. Interestingly, preantral follicle numbers decreased significantly $(P<0.05)$ when exposed to ActA + FSH. The decrease in preantral follicle number was supported by our TUNEL evaluation whereby there was a drastic shift in the proportion of healthy vs atretic follicles ( 76 vs $15 \%$ ). This suggests that the rate of atresia is increased in the preantral population receiving $A c t A+F S H$, accounting for the reduced number of preantral follicles observed. Therefore, upon activation of primordial follicles, ActA appears to be having a stimulatory effect in vitro on follicle growth and development, particularly during the primary to preantral transition as shown previously (Drummond et al. 1996, Bristol-Gould et al. 2006, McLaughlin et al. 2010, Kipp et al. 2011). However, in the presence of FSH, this stimulatory and anti-apoptotic effect was counteracted by a decrease in the proportion of healthy preantral oocytes and we conclude that these preantral follicles are dying through apoptosis. Recently, McLaughlin et al. (2010) showed that activin promoted growth and differentiation of bovine preantral follicles, possibly due to the intrafollicular cell adhesions the oocyte

Table 2 Comparison of the percentage of healthy vs atretic follicles in each follicle class after 10 days of culture.

\begin{tabular}{|c|c|c|c|c|c|c|c|c|}
\hline & \multicolumn{2}{|c|}{ Control (\%) } & \multicolumn{2}{|c|}{ FSH $(\%)$} & \multicolumn{2}{|c|}{ Activin A (\%) } & \multicolumn{2}{|c|}{ FSH + activin A (\%) } \\
\hline & Healthy & Atretic & Healthy & Atretic & Healthy & Atretic & Healthy & Atretic \\
\hline Primordial & 61 & 39 & 86 & 14 & 75 & 26 & 81 & 19 \\
\hline Primary & 62 & 38 & 58 & 42 & 90 & 10 & 84 & 16 \\
\hline Preantral & 67 & 33 & 72 & 28 & 85 & 15 & 24 & 76 \\
\hline
\end{tabular}



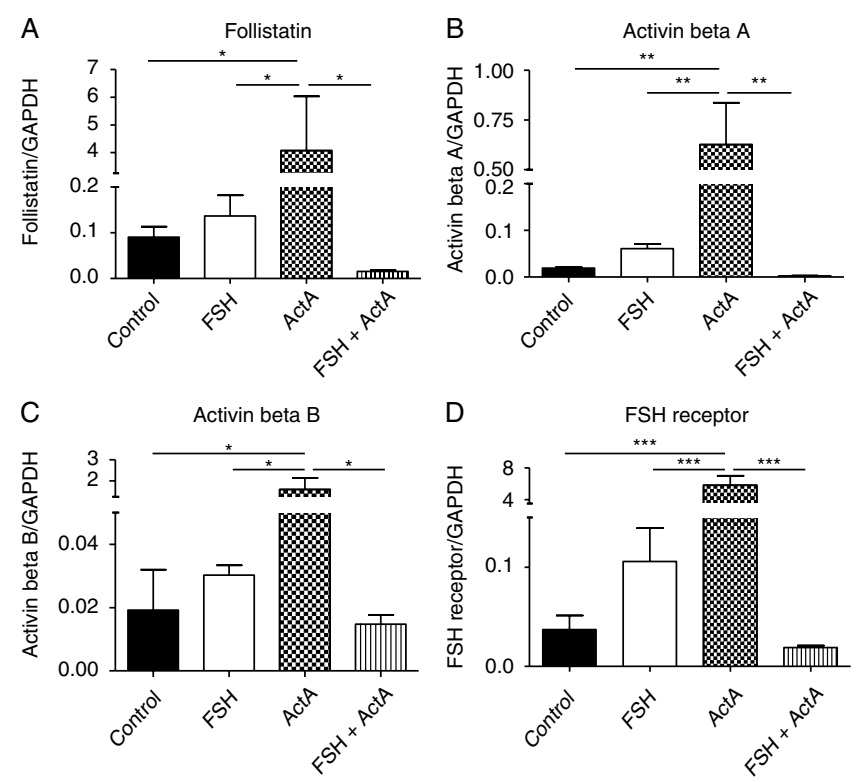

Figure 4 Expression of follistatin, activin $\beta \mathrm{A}$ and $\beta \mathrm{B}$ subunits, and FSH receptor in rat ovaries cultured for 10 days. All mRNA was normalized to Gapdh mRNA expression. Mean \pm S.E.M., $n=3 .{ }^{*} P<0.05,{ }^{*} P<0.01$, and $* * * P<0.001$ compared with control.

made with connexin 43. Taking this finding into account, it is likely that the addition of exogenous FSH at the concentration used in this study may disrupt oocyte cell adhesion interactions. This would account for the increase in atretic follicles seen in the combined ActA + FSH treatment group.

The addition of FSH and ActA to ovarian cultures blocked the transition of primary follicles to preantral follicles and may account for the decrease in FSHR mRNA expression observed. Both activin and FSH have been found to induce FSHR expression (Xiao \& Findlay 1991, Xiao et al. 1992, Nakamura et al. 1993) in a timedependent manner, peaking after $24 \mathrm{~h}$ and decreasing markedly after $48 \mathrm{~h}$ (Xiao et al. 1990, Nakamura et al. 1993). These studies, however, utilized granulosa cells from prepubertal, 25-day-old, diethylstilbestrol-treated rats, which may respond differently to the granulosa cells in our cultured rat ovaries. Furthermore, the presence of gonadotropins is not required for the initial expression of the Fshrgene and the stage of follicular development will ultimately determine the availability of the FSHR (O'Shaughnessy et al. 1994). Although preantral follicle development is part of the gonadotropin-responsive stage, these follicles do not require gonadotropins for survival but they are sensitive to their presence. Therefore, development of and transition to preantral follicles must be regulated by autocrine and paracrine mechanisms, and we have demonstrated that ActA is a potential candidate for driving this progression, confirming previous studies (Drummond et al. 1996). However, the combination of ActA + FSH resulted in preantral follicle death in our cultures. This could be due to time-dependent effects on the FSHR and to the production of inhibin. Inhibin is thought to antagonize activin action by binding to the activin type II receptor in the ovary, assisted by the presence of betaglycan (Lewis et al. 2000, Stenvers \& Findlay 2010). Inhibin is synthesized by granulosa cells with larger preantral/ antral follicles secreting higher levels of inhibin than activin (Glister et al. 2006). An upregulation of inhibin in preantral follicles is likely as expression of all three inhibin subunit mRNAs (inhibinA and $B$ and the $\alpha$-subunit) has been found in day 4 postnatal rat ovaries (Drummond et al. 2000). Ovaries from day 4 rats contain only primordial and some primary follicles; however, with the appearance of secondary and antral follicles on days 8 and 12, respectively, there was increased expression of inhibin A (Drummond et al. 2000). Increased exposure to ActA in conjunction with FSH could, therefore, be stimulating granulosa cells to upregulate the inhibin $\alpha$ subunit in preantral follicles earlier in the culture period. Inhibin has the potential to counteract the stimulatory action of ActA during early folliculogenesis, consequently blocking the progression of primary to preantral follicles. This would account for the demise of preantral follicles seen in our system.

PCR analysis revealed that activin subunits $\beta A$ and $\beta B$ as well as the FSHR were expressed at their highest levels when ovaries were treated with ActA only. Expression levels of activin $\beta B$ subunit were approximately twofold higher than that of activin $\beta$ A subunit. Earlier studies by our laboratory suggest that inhibin B is produced early in folliculogenesis (Drummond et al. 2000), accounting for the elevated activin $\beta B$ subunit levels. Interestingly, mRNA expression levels of follistatin, activin $\beta A$ and $\beta B$ subunits, and FSHR mRNAs were lowest in ovaries treated with ActA + FSH. This suggests that these ovaries may produce less inhibin after 10 days of culture. Previous work demonstrated the presence of the inhibin $\alpha$ subunit in postnatal rat ovarian tissue and cultured ovarian cells from day 4 rats (Drummond et al. 1996); the differences between the two systems may account for the suppression of follistatin, activin $\beta A$ and $\beta B$ subunits, and FSHR. Furthermore, it is important to note that follistatin is more effective than inhibin in blocking the effects of activin, although this may be dose dependent (Jeong \& Kaiser 2006). We do not know the levels of activin, inhibin, and follistatin produced by ovaries in this culture system and future studies will need to address this issue. The addition of FSH to ActA-treated cultures decreased the mRNAs of both activin subunits and FSHR when compared with the untreated control cultured ovaries. Further investigations are required to elucidate the mechanism involved. Elevated follistatin expression is most likely a result of increased activin levels present in the ActA-only treated group, given that follistatin is an activin antagonist (Shimonaka et al. 1991). As activin is known to increase the amount of FSHR available (Findlay 1993, Houben \& Denef 1994), 
it is not surprising that FSHR expression increased in ovaries treated with ActA only.

Small cultured preantral follicles obtained from adult (56-day-old) mice showed significant granulosa cell proliferation and an increase in follicle diameter when treated with FSH alone (Mizunuma et al. 1999). When treated with ActA alone, however, no significant changes were observed in the preantral follicles. These investigations demonstrate an inhibitory action of ActA on preantral follicle growth in vitro (collected from adult ovaries), which is reversible with follicles recommencing growth upon the addition of FSH (Mizunuma et al. 1999). ActA has also been shown to promote the development of small preantral follicles from 11-dayold female mice, but antagonizes the effect of FSH on preantral follicular growth in adult mice (Yokota et al. 1997). This study demonstrates activin's ability to stimulate preantral follicle growth in postnatal ovaries and supports the likelihood that the action of ActA is age dependent, having a stimulatory effect on immature follicles and an inhibitory effect on postpubertal follicles. Further investigations are needed to ascertain whether the outcomes obtained from our study apply equally to adult animals.

\section{Conclusion}

This in vitro study identified a novel action of FSH on primordial follicle apoptosis and supports a stimulatory role for ActA in the transition of primordial follicles to primary and preantral stages of development. In addition, ActA inhibited oocyte apoptosis. In addition, ovarian sensitivity to gonadotropins may play a role in inhibiting follicle development, which is demonstrated through decreased preantral follicle numbers when treated with ActA $+\mathrm{FSH}$, with apoptosis providing a means for the ovary to eliminate poor-quality oocytes. This in vitro organ culture system provides an excellent model to study the roles of other TGFB superfamily members during early folliculogenesis.

\section{Materials and Methods}

\section{Animals}

Sprague Dawley rats were obtained from Central Animal Services, Monash University (Melbourne, VIC, Australia). Ovaries were collected from untreated rats at 4 days of age for either organ culture and RNA extraction or the preparation of formalin-fixed, paraffin-embedded tissue blocks. Animals were maintained under standard conditions of lighting and temperature and they received laboratory feed pellets (estrogen free) and water ad libitum. The project was approved by the Institutional Animal Experimentation and Ethics Committee as conforming to the guidelines of the National Health and Medical Research Council of Australia.

\section{RNA extraction}

Total RNA was extracted from whole ovaries either fresh or at the end of the culture period. Ovaries were homogenized in $1 \mathrm{ml}$ Ultraspec RNA reagent (Biotec: Fisher Biotec, Melbourne, $\mathrm{VIC}$, Australia). Following an incubation for $5 \mathrm{~min}$ on ice, $0.2 \mathrm{ml}$ chloroform per milliliter of Ultraspec RNA reagent was added to the samples and they were shaken vigorously, then stored at $4{ }^{\circ} \mathrm{C}$ for $5 \mathrm{~min}$. Samples were then centrifuged for $15 \mathrm{~min}$ at $12000 \mathrm{~g}$; RNA was precipitated from the aqueous phase with 1 volume of isopropanol. The pellet was washed twice with ethanol and then air-dried and resuspended in sterile water. To ensure that the RNA was completely dissolved, the samples were incubated for $10 \mathrm{~min}$ at $60^{\circ} \mathrm{C}$. Contaminating DNA was removed from the RNA preparations using the Ambion DNA-free kit (Invitrogen). At least three independent pools of RNA were prepared for each treatment group, consisting of three ovaries per pool.

\section{Real-time PCR}

Primer pairs for follistatin, FSHR, and activin $\beta A$ and $\beta B$ subunit mRNAs were prepared using the QIAquick Gel Extraction Kit (Qiagen) as per the manufacturer's protocol (Table 3). RNA was quantified using the ND-1000 NanoDrop spectrophotometer (NanoDrop products, Wilmington, DE, USA). Complementary DNA was synthesized using Superscript III Reverse Transcriptase (Invitrogen) with all reagents supplied in the kit. Using the Applied Biosystems ABI 7900 HT Fast Real-Time machine (Melbourne, Victoria, Australia), real-time PCR samples were prepared to a final volume of $10 \mu \mathrm{l}$, with all reactions performed in triplicate. PCR conditions consisted of an initial denaturation step of $10 \mathrm{~min}$ at $95^{\circ} \mathrm{C}$, followed by 55 cycles of further denaturation $\left(95^{\circ} \mathrm{C}\right.$ for $\left.15 \mathrm{~s}\right)$, annealing $\left(61{ }^{\circ} \mathrm{C}\right.$ for $\left.5 \mathrm{~s}\right)$, and elongation $\left(72{ }^{\circ} \mathrm{C}\right.$ for $\left.8 \mathrm{~s}\right)$. Fifty-five cycles of PCR were performed to ensure the threshold crossing point (cycle number) was attained. Yields were converted to femtograms

Table 3 Rat primer sequences for real-time PCR.

\begin{tabular}{|c|c|c|c|}
\hline $\begin{array}{l}\text { Gene } \\
\text { name }\end{array}$ & $\begin{array}{l}\text { Common } \\
\text { name }\end{array}$ & $\begin{array}{l}\text { Genbank } \\
\text { accession } \\
\text { number }\end{array}$ & $\begin{array}{l}\text { Primer sequence } \\
\left(5^{\prime}-3^{\prime}\right)\end{array}$ \\
\hline Fst & Follistatin & NM012562 & $\begin{array}{l}\text { Forward: AAA CCT ACC } \\
\text { GCA ACG AAT GTG } \\
\text { Reverse: CAG GCG CTG } \\
\text { GAG TAA GTC AC }\end{array}$ \\
\hline Acta & $\begin{array}{l}\text { Activin } \beta A \\
\text { subunit }\end{array}$ & M37482 & $\begin{array}{c}\text { Forward: GGA GTG TGA } \\
\text { TGG CAA GGT CAA CA } \\
\text { Reverse: GTG GGC ACA } \\
\text { CAG CAT GAC TTA }\end{array}$ \\
\hline Actb & $\begin{array}{l}\text { Activin } \beta B \\
\text { subunit }\end{array}$ & XM344130 & $\begin{array}{l}\text { Forward ACC GGC CCT } \\
\text { TTG TAG TGG } \\
\text { Reverse: CAG CTG CCC } \\
\text { TCA CAG TAG TTC CC }\end{array}$ \\
\hline Fshr & FSH receptor & AF095642 & $\begin{array}{l}\text { Forward: GAC CAC AAG } \\
\text { CCA ATA CAA ACT AAC } \\
\text { Reverse: AAA AGC CAG } \\
\text { CAG CAT CAC AG }\end{array}$ \\
\hline Gapdh & $\begin{array}{l}\text { Glyceraldehyde- } \\
\text { 3-phosphate } \\
\text { dehydrogenase }\end{array}$ & M32599 & $\begin{array}{c}\text { Forward: GAC CCC TTC } \\
\text { ATT GAC CTC AAC } \\
\text { Reverse: GAT GAC CTT } \\
\text { GCC CAC AGC CTT }\end{array}$ \\
\hline
\end{tabular}

www.reproduction-online.org 
based on the standard curve for each PCR product and the resultant mRNA levels were normalized to the Gapdh mRNA level per sample. The data were calculated from the results of three independent experiments.

\section{Whole ovary cultures}

Whole ovaries were cultured as described previously (Parrott \& Skinner 1999, Parrott \& Skinner 2000, Nilsson et al. 2001, Rosairo et al. 2008). Briefly, whole ovaries were dissected and cultured for 10 days on floating filters $(0.4 \mu \mathrm{m}$ Millicell-CM; Millipore Corp., Billerica, MA, USA) in $0.5 \mathrm{ml}$ DMEM/Ham's F-12 medium $(1: 1, v / v)$. The medium was supplemented with penicillin and streptomycin to prevent bacterial contamination. Ovaries were randomly assigned to control or treatment groups, with three ovaries (from three separate rats) per floating filter submerged in a $30 \mu \mathrm{l}$ drop of treated DMEM/Ham's F-12 medium. The ovaries were cultured in media alone (control) or media containing ActA (50 ng/ml; R\&D Systems, Minneapolis, MN, USA), FSH (100 ng/ml; rFSH-I8, obtained from the National Hormone and Pituitary Distribution Program and the NIADDK, NIH, Bethesda, MD, USA), or a combination of ActA and FSH. Doses of treatments used in this study have been previously used by us and others (Drummond et al. 1996, Nilsson et al. 2001, Rosairo et al. 2008). Duplicate filters were used for each treatment group ( $n=6$ ovaries in total). One group $(n=3)$ of ovaries was used for histology and the other group $(n=3)$ for mRNA expression. A total of two independent experiments were conducted for histological analyses and a total of three independent experiments were conducted for mRNA expression analyses. Ovaries were cultured at $37^{\circ} \mathrm{C}$ in a humidified atmosphere containing $5 \% \mathrm{CO}_{2}$ for 10 days. Media were replaced every 2 days. At the end of the culture period, ovaries were either fixed in $10 \%$ formalin for $5 \mathrm{~h}$, embedded in paraffin, and sectioned at $5 \mu \mathrm{m}$ or used for mRNA expression. Some sections were stained with hematoxylin for morphological assessment, while others were used for immunohistochemistry/follicle counting and staining for apoptosis by TUNEL.

\section{Immunohistochemistry}

Mouse Vasa homolog (MVH; Abcam, Cambridge, UK), a germ cell-specific marker, was localized to rat oocytes in primordial, primary, and preantral stages of the development to assist in follicle counting (Fig. 1D and E). No antral follicles were observed in either fresh tissue or in ovaries at the end of culture. Sections $(5 \mu \mathrm{m})$ of formalin-fixed, paraffin-embedded rat ovaries were stained using standard immunohistochemical protocols, and Mvh-positive primordial, primary, and preantral follicles were categorized as described previously (Drummond et al. 2002, Rosairo et al. 2008). Briefly, primordial follicles consisted of oocytes surrounded by a complete or incomplete single layer of cells (either flattened or mixed with some cuboidal cells), primary follicles comprised an oocyte surrounded by a single complete layer of cuboidal granulosa cells, and preantral follicles (also known as secondary follicles) consisted of follicles with more than one complete single layer of granulosa cells.

\section{Follicle counting}

After cultured ovaries had been fixed and serially sectioned at $5 \mu \mathrm{m}$, three serial sections were mounted per slide. To assess whether the follicles were growing and progressing through the stages of folliculogenesis, follicle numbers from each follicle class were investigated. The first and third sections of every alternate slide were used for Mvh staining and subsequent counting. Primordial (475-1300), primary (125-604), and preantral (5-120) follicles were counted. Images were captured using a $\times 20$ objective and only Mvh-positive oocytes (germ cells), in which a nucleolus could be visualized, were counted using analySIS Professional Imaging Software, version 5.0 (Imaging Research, Inc., Ontario, ON, Canada; Fig. 1). A percentage distribution was determined for each follicle class from each treatment group: control, FSH, ActA, and FSH+ActA. Follicles from fresh ovaries from postnatal day 4 rats were also counted.

\section{TUNEL staining}

Apoptotic oocytes in ovarian sections were stained for using TUNEL. The ApopTag Peroxidase In Situ Apoptosis Detection Kit (Millipore, Billerica, MA, USA) was used as per the manufacturer's instructions. Ovarian sections were mounted on SuperFrost slides and treated as described previously (Rosairo et al. 2008). All samples were treated in the same experiment to avoid inter-experimental staining variability. Images were captured with a $\times 20$ objective and TdT-positively stained follicles were counted and categorized according to follicle class (primordial, primary, and secondary) using analySIS Professional Imaging Software, version 5.0 (Fig. 2). Oocytes that stained positively for the TdT enzyme were deemed 'atretic' compared with those that remained unstained which were categorized as 'healthy'. TdT-positive somatic cells were present; however, for the purpose of this study, only TdTpositive oocytes were counted. Atretic follicles (TdT-positive oocyte) vs healthy follicles are represented as a percentage of the total number of follicles within a follicle class.

\section{Statistical analyses}

Statistical significance was determined using GraphPad Prism 4.03 (GraphPad Software, Inc., La Jolla, CA, USA) by ANOVA in conjunction with Tukey's post-hoc test. Cultured ovaries used for classification and counting purposes were repeated twice ( $n=3$ for each experiment) while mRNA expression experiments were repeated at least three times $(n=3$ per treatment group in each experiment). $P$ values $<0.05$ compared with the appropriate control were regarded as statistically significant.

\section{Declaration of interest}

The authors declare that there is no conflict of interest that could be perceived as prejudicing the impartiality of the research reported. 


\section{Funding}

This work was supported by the National Health and Medical Research Council of Australia (Regkey \#494802 and \#441101; The Victorian Government's Operational Infrastructure Support Program. Prince Henry's Institute Data Audit 11-06).

\section{Acknowledgements}

The authors would like to thank Dr Maree Bilandzic for her assistance with the real-time PCR procedures. They also thank Sue Panckridge for her assistance in the preparation and submission of the manuscript.

\section{References}

Bristol-Gould SK, Kreeger PK, Selkirk CG, Kilen SM, Cook RW, Kipp JL, Shea LD, Mayo KE \& Woodruff TK 2006 Postnatal regulation of germ cells by activin: the establishment of the initial follicle pool. Developmental Biology 298 132-148. (doi:10.1016/j.ydbio.2006.06. 025)

Ding CC, Thong KJ, Krishna A \& Telfer EE 2010 Activin A inhibits activation of human primordial follicles in vitro. Journal of Assisted Reproduction and Genetics 27 141-147. (doi:10.1007/s10815-010-9395-6)

Drummond AE 2005 TGFbeta signalling in the development of ovarian function. Cell and Tissue Research 322 107-115. (doi:10.1007/s00441. 005-1153-1)

Drummond AE, Dyson M, Mercer JE \& Findlay JK 1996 Differential responses of post-natal rat ovarian cells to $\mathrm{FSH}$ and activin. Molecular and Cellular Endocrinology 122 21-32. (doi:10.1016/03037207(96)03867-1)

Drummond AE, Dyson M, Thean E, Groome NP, Robertson DM \& Findlay JK 2000 Temporal and hormonal regulation of inhibin protein and subunit mRNA expression by post-natal and immature rat ovaries. Journal of Endocrinology 166 339-354. (doi:10.1677/joe.0.1660339)

Drummond AE, Le MT, Ethier JF, Dyson M \& Findlay JK 2002 Expression and localization of activin receptors, Smads, and beta glycan to the postnatal rat ovary. Endocrinology 143 1423-1433. (doi:10.1210/en. 143.4.1423)

Findlay JK 1993 An update on the roles of inhibin, activin, and follistatin as local regulators of folliculogenesis. Biology of Reproduction 48 15-23. (doi:10.1095/biolreprod48.1.15)

Funkenstein B, Nimrod A \& Lindner HR 1980 The development of steroidogenic capability and responsiveness to gonadotropins in cultured neonatal rat ovaries. Endocrinology 106 98-106. (doi:10.1210/endo106-1-98)

Glister C, Groome NP \& Knight PG 2006 Bovine follicle development is associated with divergent changes in activin- $\mathrm{A}$, inhibin-A and follistatin and the relative abundance of different follistatin isoforms in follicular fluid. Journal of Endocrinology 188 215-225. (doi:10.1677/joe.1.06485)

Gosden R \& Telfer E 1987 Scaling of follicular sizes in mammalian ovaries. Journal of Zoology 211 157-168. (doi:10.1111/j.1469-7998.1987. tb07459.x)

Houben H \& Denef C 1994 Bioactive peptides in anterior pituitary cells. Peptides 15 547-582. (doi:10.1016/0196-9781(94)90218-6)

Jeong K \& Kaiser U 2006 Gonadotropin-releasing hormone regulation of gonadotropin biosynthesis and secretion. In Knobil and Neill's Physiology of Reproduction, p 1659.Ed. JD Neill. California: Elsevier.

Katamaya T, Shiota K \& Takahashi M 1990 Activin A increases the number of follicle-stimulating hormone cells in anterior pituitary cultures. Molecular and Cellular Endocrinology 69 179-185. (doi:10.1016/ 0303-7207(90)90011-V)

Kipp JL, Goleebiowski A, Rodriguez G, Demczuk M, Kilen SM \& Mayo KE 2011 Gene expression profiling reveals Cyp26b1 to be an activin regulated gene involved in ovarian granulosa cell proliferation. Endocrinology 152 303-312. (doi:10.1210/en.2010-0749)
Knight PG 1996 Roles of inhibins, activins, and follistatin in the female reproductive system. Frontiers in Neuroendocrinology 17 476-509. (doi:10.1006/frne.1996.0013)

Lewis KA, Gray PC, Blount AL, MacConell LA, Wiater E, Bilezikjian LM \& Vale W 2000 Betaglycan binds inhibin and can mediate functional antagonism of activin signalling. Nature 404 411-414. (doi:10.1038/ 35006129)

Massague J 1998 TGF-beta signal transduction. Annual Review of Biochemistry 67 753-791. (doi:10.1146/annurev.biochem.67.1.753)

McLaughlin M, Broomfield JJ, Albertini DF \& Telfer EE 2010 Activin promotes follicular integrity and oogenesisi in cultured preantral bovine follicles. Molecular Human Reproduction 9 644-653. (doi:10.1093/ molehr/gaq021)

Meunier H, Rivier C, Evans RM \& Vale W 1988 Gonadal and extragonadal expression of inhibin alpha, beta A, and beta B subunits in various tissues predicts diverse functions. PNAS 85 247-251. (doi:10.1073/pnas.85.1. 247)

Mizunuma H, Liu X, Andoh K, Abe Y, Kobayashi J, Yamada K, Yokota H, Ibuki Y \& Hasegawa Y 1999 Activin from secondary follicles causes small preantral follicles to remain dormant at the resting stage. Endocrinology 140 37-42. (doi:10.1210/en.140.1.37)

Nakamura M, Minegishi T, Hasegawa Y, Nakamura K, Igarashi S, Ito I, Shinozaki H, Miyamoto K, Eto Y \& Ibuki Y 1993 Effect of an activin A on follicle-stimulating hormone $(\mathrm{FSH})$ receptor messenger ribonucleic acid levels and FSH receptor expressions in cultured rat granulosa cells. Endocrinology 133 538-544. (doi:10.1210/en.133.2.538)

Nilsson E, Doraiswamy V, Parrott JA \& Skinner MK 2001 Expression and action of transforming growth factor beta (TGFbeta1, TGFbeta2, TGFbeta3) in normal bovine ovarian surface epithelium and implications for human ovarian cancer. Molecular and Cellular Endocrinology 182 145-155. (doi:10.1016/S0303-7207(01)00584-6)

O'Shaughnessy PJ, Marsh P \& Dudley K 1994 Follicle-stimulating hormone receptor mRNA in the mouse ovary during post-natal development in the normal mouse and in the adult hypogonadal (hpg) mouse: structure of alternate transcripts. Molecular and Cellular Endocrinology 101 197-201. (doi:10.1016/0303-7207(94)90235-6)

Parrott JA \& Skinner MK 1999 Kit-ligand/stem cell factor induces primordial follicle development and initiates folliculogenesis. Endocrinology 140 4262-4271. (doi:10.1210/en.140.9.4262)

Parrott JA \& Skinner MK 2000 Kit ligand actions on ovarian stromal cells: effects on theca cell recruitment and steroin production. Molecular Reproduction and Development 55 55-64. (doi:10.1002/(SICI)10982795(200001)55:1 < 55::AID-MRD8 > 3.0.CO;2-L)

Rabinovici J, Spenser S, Doldi N, Goldsmith P, Schwall R \& Jaffe R 1992 Activin-A as an intraovarian modulator: actions, localization, and regulation of the intact dimer in human ovarian cells. Journal of Clinical Investigation 89 1528-1536. (doi:10.1172/JCl115745)

Rajah R, Glaser EM \& Hirshfield AN 1992 The changing architecture of the neonatal rat ovary during histogenesis. Developmental Dynamics 194 177-192. (doi:10.1002/aja.1001940303)

Roberts VJ, Barth S, el-Roeiy A \& Yen SS 1993 Expression of inhibin/activin subunits and follistatin messenger ribonucleic acids and proteins in ovarian follicles and the corpus luteum during the human menstrual cycle. Journal of Clinical Endocrinology and Metabolism 77 1402-1410. (doi:10.1210/jc.77.5.1402)

Rosairo D, Kuyznierewicz I, Findlay J \& Drummond A 2008 Transforming growth factor-beta: its role in ovarian follicle development. Reproduction 136 799-809. (doi:10.1530/REP-08-0310)

Shimonaka M, Inouye S, Shimasaki S \& Ling N 1991 Follistatin binds to both activin and inhibin through the common subunit. Endocrinology 128 3313-3315. (doi:10.1210/endo-128-6-3313)

Sidis Y, Fujiwara T, Leykin L, Isaacson K, Toth T \& Schneyer AL 1998 Characterization of inhibin/activin subunit, activin receptor, and follistatin messenger ribonucleic acid in human and mouse oocytes: evidence for activin's paracrine signaling from granulosa cells to oocytes. Biology of Reproduction 59 807-812. (doi:10.1095/biolreprod59.4.807)

Silva JR, Tharasanit T, Taverne MA, van der Weijden GC, Santos RR, Figueiredo JR \& van den Hurk R 2006 The activin-follistatin system and in vitro early follicle development in goats. Journal of Endocrinology $\mathbf{1 8 9}$ 113-125. (doi:10.1677/joe.1.06487) 
Sokka T \& Huhtaniemi I 1990 Ontogeny of gonadotrophin receptors and gonadotrophin-stimulated cyclic AMP production in the neonatal rat ovary. Journal of Endocrinology 127 297-303. (doi:10.1677/joe.0. 1270297)

Stenvers KL \& Findlay JK 2010 Inhibins: from reproductive hormones to tumor suppressors. Trends in Endocrinology and Metabolism 21 174-180. (doi:10.1016/j.tem.2009.11.009)

Vale W, Rivier J, Vaughan J, McClintock R, Corrigan A, Woo W, Karr D \& Spiess J 1986 Purification and characterization of an FSH releasing protein from porcine ovarian follicular fluid. Nature 321 776-779. (doi:10.1038/321776a0)

Vendola KA, Zhou J, Adesanya OO, Weil SJ \& Bondy CA 1998 Androgens stimulate early stages of follicular growth in the primate ovary. Journal of Clinical Investigation 101 2622-2629. (doi:10.1172/ $\mathrm{JCl} 2081)$

Woodruff TK \& Mather JP 1995 Inhibin, activin and the female reproductive axis. Annual Review of Physiology 57 219-244. (doi:10.1146/annurev. ph.57.030195.001251)

Xiao S \& Findlay JK 1991 Interactions between activin and folliclestimulating hormone-suppressing protein and their mechanisms of action on cultured rat granulosa cells. Molecular and Cellular Endocrinology 79 99-107. (doi:10.1016/0303-7207(91)90100-7)
Xiao S, Findlay JK \& Robertson DM 1990 The effect of bovine activin and follicle-stimulating hormone (FSH) suppressing protein/follistatin on $\mathrm{FSH}$-induced differentiation of rat granulosa cells in vitro. Molecular and Cellular Endocrinology 69 1-8. (doi:10.1016/0303-7207(90)90082-J)

Xiao S, Robertson DM \& Findlay JK 1992 Effects of activin and folliclestimulating hormone (FSH)-suppressing protein/follistatin on $\mathrm{FSH}$ receptors and differentiation of cultured rat granulosa cells. Endocrinology 131 1009-1016. (doi:10.1210/en.131.3.1009)

Yokota H, Yamada K, Liu X, Kobayashi J, Abe Y, Mizunuma H \& Ibuki Y 1997 Paradoxical action of activin A on folliculogenesis in immature and adult mice. Endocrinology 138 4572-4576. (doi:10.1210/en.138.11.4572)

Zhao J, Taverne MA, Van der Weijden GC, Bevers MM \& van den Hurk R 2001 Effest of activin A on in vitro development of rat preantral follicles and localization of activin A and activin receptor II. Biology of Reproduction 65 967-977. (doi:10.1095/biolreprod65.3.967)

Received 4 April 2011

First decision 13 June 2011

Revised manuscript received 10 November 2011

Accepted 21 November 2011 